\title{
The role of succession in temporal cognition: Is the time-order error a recency effect of memory?
}

\author{
FRANK R. SCHAB and ROBERT G. CROWDER \\ Yale University, New Haven, Connecticut
}

\begin{abstract}
Two experiments were conducted to investigate the presentation-order error that occurs in judgments of sequentially presented temporal intervals. The factors of interest were (1) the source of the errors, sensitivity versus bias, (2) the direction of the errors, and (3) the effect of varying the ISI separating the sequentially presented intervals. Subjects experienced two successively presented time intervals in the range of 1 to $4 \mathrm{sec}$ or 10 to $13 \mathrm{sec}$ on each trial, separated by ISIs of .5-6 sec, and were asked to reproduce either the first or the second interval. Results indicated a negative time-order error for all intervals, such that the intervals were consistently reproduced as longer when presented second rather than first. This time-order error was found to be due to the sensitivity of the processing system, and was interpreted in terms of the recency effect of memory. Presentation order was found to affect sensitivity, whereas ISI was shown to affect reliability of reproductions. ISI had no systematic effect on the size of the time-order error. Implications for time-order error theories and the general importance of the study of presentationorder effects are discussed.
\end{abstract}

Fechner (1860) was the first psychologist to discover and speculate about the nature and cause of the systematic error that generally affects subjects' judgments of sequentially presented stimuli: When discriminating between a pair of successively lifted weights, Fechner observed that the probability of a correct judgment was greater when he first lifted the lighter of the two weights rather than the other way around. Fechner subsequently distinguished between a negative discrimination error (better discrimination when the first stimulus is less than the second) and a positive one (better discrimination when the first stimulus is greater than the second).

This presentation-order error, more commonly known as time-order error (TOE), has been the subject of theoretical and empirical attention since the early days of experimental psychology (for comprehensive reviews, see Guilford, 1954; Hellström, 1985; Needham, 1934; Woodrow, 1935), and appropriately so: successive stimulus presentation is ubiquitous in cognitive psychological research, and knowledge regarding systematic errors in judgment that occur on the basis of the order in which stimuli are presented is of vital importance for the interpretation of such research. Beyond the psychology lab, successive judgments are probably also more common than simultaneous judgments, and are evidenced, for example, in such varied behaviors as comparing musical per-

Research and preparation of this article was supported in part by $\mathrm{Na}$ tional Science Foundation Grant BNS 92-19661. We gratefully acknowledge the helpful comments made by Alfred B. Kristofferson, Lorraine G. Allan, and an anonymous reviewer on an earlier draft of this article. Correspondence concerning this article should be addressed to Frank R. Schab, Department of Psychology, Yale University, P.O. Box 11 A Yale Station, New Haven, CT 06520-7447. formances, tasting wines, shopping for a new car, and so forth. The study of sequential stimulus presentation in the lab may thus not only be fruitful, but necessary, for, as Hellström (1985) aptly remarked: "What happens when we compare two successive stimuli may serve as a model for what happens when we perform judgments, comparisons, and decisions in general" (p. 57).

In contrast to the first three decades of this century, however, recent interest in the phenomenon of the TOE has been modest, at best. This lack of interest among current researchers is surprising, given that the proportion of correct judgments can vary by up to $80 \%$ (e.g., Jamieson \& Petrusic, 1975a), depending on the order in which stimuli are presented. Moreover, presentation-order effects also seem to be quite general in that they are found across many different stimulus modalities: Time-order errors have been obtained in judgments of loudness, heaviness, brightness, taste, and duration (e.g., Woodworth, 1938), and, albeit less frequently and more controversially, in judgments of pitch (e.g., Tresselt, 1948) and hurtfulness (e.g., Geertsma, 1958). Furthermore, TOEs are not restricted to discrimination tasks; they have also been found in experiments that employed scaling procedures, including, for example, the method of reproduction (e.g., Eisler, 1975; Postman, 1947). Modem neglect of the TOE is thus in stark contrast to the apparent importance and generality of the phenomenon. This discrepancy, however, may be due to the inconclusive, and thus unsatisfactory, search for the cause of these presentationorder effects, an issue we address in this paper.

The TOE is defined by its magnitude and direction. With regard to direction, the most common finding is a negative TOE, in which the first of two stimuli is under- 
estimated relative to the second. In temporal judgment, which will be the focus of this paper, the general finding is that when both short and long intervals are presented in the same experiment, a positive TOE (overestimation of the first interval) occurs for the short intervals and a negative TOE (overestimation of the second interval) $\alpha c-$ curs for the longer intervals (e.g., Fraisse, 1948; Stott, 1935; Vierordt, 1868; Woodrow, 1935). More recently, Jamieson and Petrusic (1975a) have challenged this generalization, suggesting instead that positive TOEs obtain when the stimulus range is restricted and that negative TOEs obtain when the stimulus range is wide.

Using two short (300 and $375 \mathrm{msec}$ ) and two long $(5,000$ and 5,400 msec) intervals, Jamieson and Petrusic (1975a) demonstrated a positive TOE when subjects were presented with comparison trials consisting only of short intervals and a negative TOE when trials consisting of the longer intervals were combined with trials containing short intervals. Moreover, with regard to TOE magnitude, Jamieson and Petrusic (1975a, 1975b, Experiment 3) found that the size of the TOE was a monotonically decreasing function of the interstimulus interval (ISI) separating the two stimulus intervals, which ranged from .5 to $8 \mathrm{sec}$ in their experiments. This finding is surprising in light of the fact that nearly all early research on the TOE had demonstrated a positive relationship between TOE magnitude and length of the ISI, such that as the interval separating the two target stimuli increased, TOE magnitude increased proportionately (e.g., Fechner, 1860; Köhler, 1923; Stärke, 1886; Wolfe, 1898). However, while the nature of the relationship between ISI and presentation-order effects is important to any complete understanding of presentation-order effects, and is manipulated in the present study, the investigation of ISI effects without a guiding theory seems meaningless. Thus, the primary purpose of the experiments that follow was to investigate the cause of the TOE.

In accordance with modern psychophysics, interest in the TOE in recent years has concentrated on whether the TOE is due to functional sensitivity of the human timekeeping system or, alternatively, is the result of a bias. The early TOE theories (e.g., Boas, 1882; Fechner, 1860; Köhler, 1923), as well as a more recent hypothesis (Ornstein, 1969), regarded the TOE as a perceptual or memorial phenomenon, the most common idea being that the mental representation of the first stimulus deteriorates, in strength or detail, and that the comparison is between the faded image of the first stimulus and the fresher trace of the second. These "fading-trace" theories were well supported by findings of predominantly negative TOEs and a positive correlation between TOE magnitude and ISI (as the ISI increases, the memory image of the first stimulus fades more and more), but could not account for positive TOEs.

Köhler (1923) suggested a physiological trace model to account for both positive and negative TOEs, and proposed that when the ISI was less than $3 \mathrm{sec}$, the effective value of the first stimulus would be greater than its ob- jective value, resulting in a positive TOE. With ISIs longer than $3 \mathrm{sec}$, Köhler assumed that a "sinking" of the physiological trace of the first stimulus would lead to negative TOEs. However, neither Köhler's theory nor any of the other major representatives of fading-trace theory can account for the finding that TOEs are affected by stimuli interpolated into the ISI (Lauenstein, 1933). Nor can this view be reconciled with the results reported by Jamieson and Petrusic (1975a, 1975b), which showed a continuous decrease in TOE magnitude with increasing ISIs. Modern versions of perceptual-memorial theories include sensation weighting (e.g., Hellström, 1977, 1985) and assimilation/adaptation-level (Helson, 1964; Woodrow, 1933,1935 ) interpretations of the TOE, which predict that ISI length and TOE magnitude are positively related and that positive TOEs will obtain for short intervals and negative TOEs will obtain for long intervals.

More recently, several theorists have attributed TOE effects to response biases. The proposed bias explanations of the TOE include simple response-bias interpretations, in which subjects prefer, for example, to respond with "second interval longer" (e.g., Engen, 1971; Luce, 1959), and more sophisticated criterion bias interpretations (e.g., Allan, 1977; Luce \& Galanter, 1963), in which the TOE is attributed to the combined effects of stimulus magnitude and an acquired criterion in the decision process. It remains unclear, however, how bias theories of the TOE can account for the TOE's apparent dependence on ISI length, stimuli interpolated in the ISI, and stimulus range.

The confusion surrounding the cause of the TOE, which, as we indicated above, may be the major reason for the decline of interest in presentation-order effects, is due, in large part, to the measures employed in most TOE experiments. The commonly used variables of proportion correct and degree of over- and underestimation do not easily permit disentanglement of (1) sensitivity of the psychological timing apparatus to changes in physical time from (2) subjects' experience-based biases.

In the context of frequency judgments, Naveh-Benjamin and Jonides (1986) used the slopes of regression lines relating actual and estimated frequency of occurrence as a measure of sensitivity to variations in frequency. These researchers correctly argued that the slope of the function relating estimated and actual frequency of occurrence is an indicator of sensitivity to frequency variation: As the slope of the regression line relating estimated and actual frequency approaches unity, subjects are increasingly sensitive to variations in actual frequency. In the time literature, a similar analysis has been employed on temporal discrimination performance in animals (e.g., Fetterman \& Dreyfus, 1987; Stubbs, 1976). Recently, Crowder and Greene (1987) have suggested that construction and analysis of the linear regression function relating temporal judgments to physical time permits separation of sensitivity (slope) and bias (intercept) effects, provided, of course, the relationship between temporal judgments and physical time is linear. The slope of such a regression line 
measures how "fast" temporal judgment of duration changes as a function of physical duration. Steeper slopes correspond to greater sensitivity, because larger changes in temporal judgment occur as a function of changes in physical time. A response bias, on the other hand, would not change this sensitivity measure but would, instead, affect the intercept value of the relationship, reflecting subjects' preferences for judging one interval longer or shorter than the other.

Another measure of interest besides slope and intercept is the variability of judgments with respect to the linear function describing them. Greater variability, as reflected, for example, in a low $r^{2}$ value, corresponds to less reliability or consistency in the judgments. In a sense, such variability is also a measure of sensitivity though, because it indicates the extent to which judgments change as a function of repetition. If, for example, judgments on a given stimulus vary considerably from one trial to the next, then subjects are not sensitive to the magnitude of that stimulus, regardless of the slope or intercept values. This variability thus represents a slightly different form of sensitivity than does slope: Variability is a function of sensitivity to the same stimulus over time, whereas slope is a function of sensitivity to changes in stimulus magnitude.

In the present study, we employed an analysis in terms of the above-mentioned variables to investigate whether the TOE in temporal cognition is the result of sensitivity or bias. In our experiments, subjects were presented with two intervals on each trial and were required to reproduce either the first or second interval. Given the ample evidence in the literature supporting a linear relationship between physical and reproduced time (see, e.g., Allan, 1978), we reasoned that if the TOE was due to sensitivity, then a difference should obtain between the slopes of the regression lines fit to reproductions of intervals presented first and second. To calculate meaningful regression functions, however, one requires judgments over a range of intervals. Previous studies of the TOE have, unfortunately, used too few time intervals, mostly two or even only one interval (e.g., Woodrow, 1933, 1935), to allow for the construction of reliable regression functions and, through them, the separation of sensitivity and bias. The present study employed a relatively wide range of intervals to permit the construction of interpretable regression lines.

In summary, the goal of the following experiments was to examine the TOE in terms of its source (sensitivity vs. bias), its direction for both relatively short and long intervals (positive vs. negative), and, finally, its relation to ISI length (positive vs. inverse).

\section{EXPERIMENT 1}

Experiment 1 was designed to document the TOE phenomenon for relatively short and long intervals, using the method of reproduction, and to construct linear regression functions, relating reproduced time to physical time, for intervals presented in either the first or the second serial positions in order to distinguish sensitivity effects from bias effects as described above.

\section{Method}

Subjects. Twenty subjects participated in Experiment 1, all recruited from the Yale summer community and paid for their services. None of the subjects had ever participated in a time experiment.

Stimuli and Apparatus. The entire experiment, including stimulus presentation and response collection, was controlled by an IBM PC AT computer with an attached color graphics monitor. A total of eight stimulus intervals, arranged in two categories of short (1, $2,3$, and $4 \mathrm{sec})$ and long $(10,11,12$, and $13 \mathrm{sec})$ intervals, were used. The beginnings and endings of all intervals were marked by a 1,000-cps tone lasting $250 \mathrm{msec}$ from onset to offset. The intensity of the tone was constant throughout the experiment.

Design and Procedure. Each trial consisted of the sequential presentation of two intervals separated by an ISI of $2 \mathrm{sec}$, followed by a visual cue that indicated to subjects which interval, first or second, to reproduce. One of the intervals was the test interval, the one to be reproduced; the other interval was chosen randomly from the same category (short or long) as the test interval. Each of the eight stimulus intervals was presented as the test interval four times in each of the two serial positions, yielding a total of 64 trials. Trial order was randomized across subjects.

Both time intervals of every trial were filled with an arithmetic task that served as a distractor task in order to prevent deliberate counting. Immediately following the tone that signaled the start of an interval, a $4 \times 4$ matrix of randomly generated two-digit numbers in the range of $\mathbf{1 0}$ to $\mathbf{4 0}$ appeared on the computer monitor, and the subjects' task was to add adjacent numbers together continuously and to pronounce the result of each addition aloud. Throughout the experiment, the subjects' responses on this task were tape-recorded, and the subjects were informed of this. Furthermore, the subjects were told that the addition task was a "crucial part of the experiment." The tape recorder was in plain view and was activated while the subjects looked on. The matrix of numbers disappeared from the computer screen with the onset of the tone that marked the end of the interval. The subjects' performance on the addition task was not, in fact, saved or analyzed.

A trial began with the word "ready" presented in the center of the computer screen for $1 \mathrm{sec}$, followed by presentation of the first interval, an empty ISI of $2 \mathrm{sec}$, and the second interval. One second after presentation of the second interval, the computer informed subjects, through a visual message centered on the monitor, which interval to reproduce, the first or second. Prior to this response prompt, the subjects were unaware of which interval was the test interval. The cued interval was reproduced by depressing the space bar on the keyboard once to start, and again to stop, interval reproduction. Two seconds after interval reproduction, a new trial was initiated.

The subjects were informed at the outset that all intervals were in the range of 1 through $20 \mathrm{sec}$ and were all integer values.

\section{Results and Discussion}

Table 1 shows the mean reproductions for each of the eight stimulus intervals as a function of presentation position (first or second). The most apparent feature of Table 1 is the negative TOE at all but the $1-\sec$ stimulus interval, where reproductions were essentially identical regardless of presentation position: When the target interval was presented as the second of the pair, reproductions were consistently longer than when the firstpresented interval was cued. The overall mean reproductions for intervals presented first and second were $\mathbf{4 . 3 5}$ 
Table 1

Mean Interval Reproductions as a Function of Stimulus Interval (in Seconds) and Presentation Position for Experiment 1

\begin{tabular}{rrrrrrrrrr}
\hline & \multicolumn{8}{c}{ Stimulus Interval } \\
\cline { 2 - 9 } & \multicolumn{1}{c}{} & \multicolumn{1}{c}{2} & \multicolumn{1}{c}{3} & 4 & 10 & 11 & 12 & 13 \\
\hline Position 1 & $M$ & 1.43 & 1.73 & 2.40 & 2.90 & 5.78 & 6.98 & 6.81 & 6.81 \\
& $S D$ & 1.23 & .86 & 1.11 & 1.24 & 2.45 & 2.94 & 2.87 & 3.23 \\
Position 2 $M$ & 1.19 & 2.02 & 2.65 & 3.32 & 7.06 & 7.56 & 7.81 & 9.06 \\
& $S D$ & .57 & .94 & 1.14 & 1.13 & 1.93 & 2.34 & 2.73 & 2.61 \\
\hline
\end{tabular}

and $5.09 \mathrm{sec}$, respectively, and this presentation-order effect was statistically significant $[F(1,19)=25.07$, $p<.001$ ] (the true overall mean was $7.0 \mathrm{sec}$ ). Sixteen of the 20 subjects showed a negative TOE, and 4 demonstrated a positive one ( $p=.0046$ by a sign test). Experiment 1 , in showing a negative TOE for both short and long intervals, is thus at odds with the early empirical studies, which showed positive TOEs for short intervals and negative ones for longer intervals, but is congruent with the hypothesis of Jamieson and Petrusic (1975a, 1975b) that a wide stimulus range, such as the one employed here, results in universally negative TOEs. However, since stimulus range was not manipulated in the present experiments, we can comment on this result only in passing.

Figure 1, which shows the mean reproductions of Table 1 with the best-fitting linear regression lines for both presentation positions, suggests, further, that the TOE is due to greater sensitivity of the timing mechanism to objective time in the second interval than in the first, rather than to bias: mean reproductions for presentation positions 1 and 2 differ primarily in slope and not in intercept. The argument employed here is as follows: If the TOE were the result of bias, then one would expect no significant difference in the slopes of the regression functions relating reproduced and physical time, but only an intercept difference. A bias would shift the function up or down on the ordinate, reflecting subjects' preferences for judging the first or the second interval as having been the longer, and the regression functions for both serial positions would otherwise be parallel. If, on the other

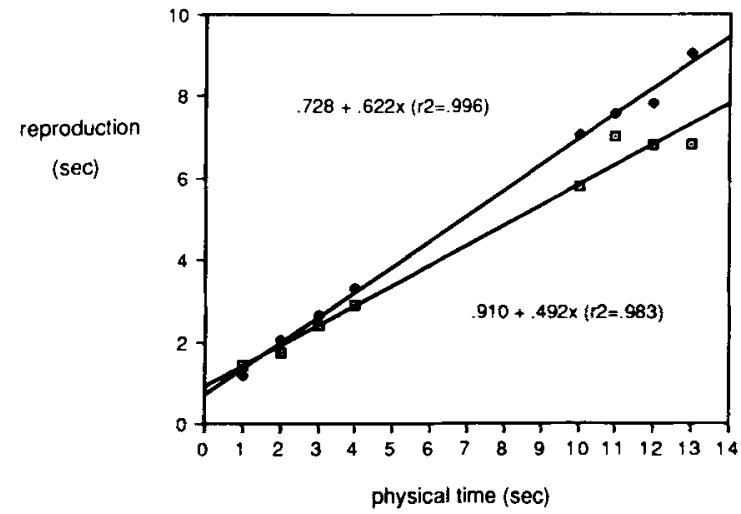

Figure 1. Mean reproductions for all eight stimulus intervals and both presentation positions in Experiment 1. - = position 1; position 2. hand, the TOE is the result of sensitivity of the processing system, then a slope difference should exist, reflecting differential processing of intervals presented first and second. Admittedly, an advocate of the bias interpretation of the TOE could propose a sophisticated changingbias theory to explain slope effects, but such an argument, we believe, is moot, because in that case, the conceptual distinction between sensitivity effects and bias effects becomes clouded and of little theoretical use.

To test slope and intercept differences between the two presentation orders in the present experiment, regression slopes and intercepts for both first and second presentation order were calculated for each subject and submitted to an analysis of variance. The results revealed a significant slope difference between first and second positions $[F(1,19)=22.16, p<.001]$, with a greater mean slope for intervals presented second (.622) than for those presented first (.492), but no reliable difference in intercepts $[.983$ vs. $.728 ; F(1,19)=3.07, p>.05]$. Thus, Experiment 1 indicates that the TOE is the result of sensitivity of the processing system to the temporal order in which the stimulus intervals are presented: perceptual and/or memorial processing residue of the more recent of two temporal intervals seems to be systematically different from a temporally more remote interval. The negative, sensitivity-based TOE found in the present experiment lends support to the original fading-trace theories in which the image of the first interval fades relative to the second. But the result provides no evidence for assimilation and adaptation-level interpretations which predict positive TOEs for the short intervals and negative ones for the long intervals; nor does it support bias theories, which predict intercept and not slope differences.

A modern comment on fading-trace theory is that the negative TOE simply represents the familiar recency effect in memory (see, e.g., Baddeley \& Hitch, 1977; Bjork \& Whitten, 1974; Crowder, 1976; Glanzer \& Cunitz, 1966; Watkins \& Peynircioglu, 1983), provided there is a slope difference such as we found in Experiment 1. According to this interpretation, the negative TOE occurs because the information used in reproducing the first of two intervals is less accessible than the information used in reproducing the second interval. The realization that a slope-based, negative TOE is tantamount to the same memory process responsible for the recency effect could integrate the relatively restricted research area on the TOE with the large and well-defined field of recency research and, more importantly, explain the effect of succession on stimulus judgment in terms of general principles of memory. We should like to point out, however, that this reasoning only suggests a direction in which to look for an interpretation; the memory recency effect is familiar, but not at all settled theoretically (see, e.g., Greene, 1986).

\section{EXPERIMENT 2}

The main finding of Experiment 1 was a generally negative TOE that resulted from the greater sensitivity of the 
time-keeping system to changes in physical time with respect to the second rather than the first of two intervals. The first goal of Experiment 2 was to replicate the major finding of Experiment 1, a sensitivity-based, negative TOE. Second, we reasoned that if the TOE were a form of recency, then manipulating the interstimulus interval separating the two intervals presented on each trial should have a predictable effect: As the interstimulus interval increases, memory, and thus reproduction performance, for the first interval should become less consistent, and thus less reliable. This prediction resulting from a recency interpretation of the TOE contrasts with alternative explanations of the TOE, such as assimilation/adaptation-level theories and bias theories, which make no predictions regarding the relationship between TOE magnitude and ISI length.

\section{Method}

Subjects. A total of 53 paid volunteers from the Yale summer community participated in Experiment 2 . All subjects reportedly had never participated in a time experiment.

Design and Procedure. The stimuli, apparatus, and procedures of Experiment 2 were essentially identical to those of Experiment 1, with the major exception of the interstimulus interval separating the first and second intervals.

The three sections of Experiment 2 were originally considered as separate experiments, but are reported here as a single investigation for ease of exposition. In the first section, the two intervals on every trial were separated by either a 1- or a 6-sec ISI, and this completely within-subjects design resulted in a 96-trial, 75-min session per subject. Many of the 17 subjects who participated in Section 1, however, reported becoming fatigued after about two-thirds of the experimental session, and this problem was dealt with in two ways. First, the subjects' reproductions to only the first 48 trials of each session were considered for analysis. Since trial order was randomized across subjects, this procedure did not selectively favor any experimental condition. Second, Section 2 used the same two ISIs as Section 1, 1 and $6 \mathrm{sec}$, but contained fewer trials by making ISI length a between-subjects factor. Nine subjects participated in each of the two ISI conditions of Section 2. Section 3 employed a .5- and 4-sec ISI with 9 subjects in each ISI condition, and was otherwise identical to Section 2 . Subjects in Sections 2 and 3 were assigned randomly to one of the two ISI conditions.

\section{Results and Discussion}

TOE and sensitivity. Table 2 and Panels 1 and 2 of Figure 2 present the results of Section 1 for the 1 - and 6-sec ISIs. The entries in Figure 2, as in Figure 1, are the mean interval reproductions for both presentation orders, and the lines represent the least-squares regression lines for both serial positions. Both panels show a negative TOE for the short and long intervals; the interval reproductions were longer for the intervals presented as the second of the pair than for the intervals presented first. This presentation-order effect, collapsed over ISI, was statistically significant $[F(1,16)=10.15, p<.01]$, with 15 of the 17 subjects showing a negative TOE ( $p=.001$ by a sign test). Having thus established a reliable TOE, the question was whether this TOE was the result of sensitivity, as suggested by Experiment 1, or bias. Accordingly, the regression lines in Panels 1 and
Toble 2

Mean Interval Reproductions as a Function of Stimulus Interval (in Seconds) and Presentation Position for Experiment 2, Section 1 Stimulus Interval

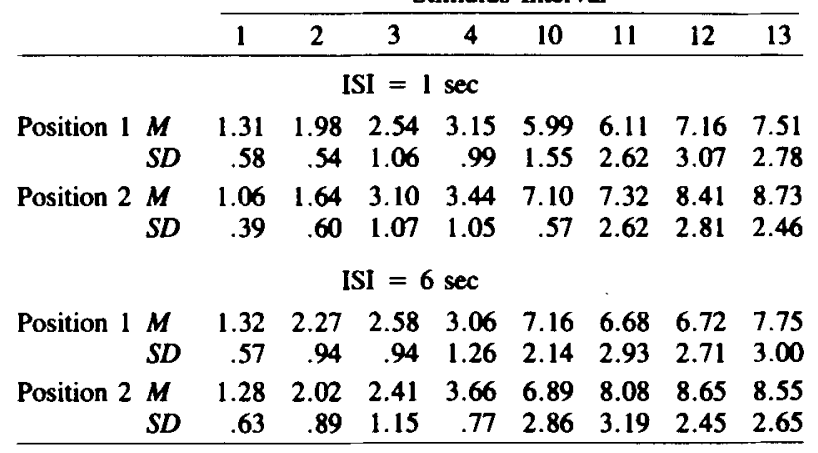

2 indicate that slope differences, rather than intercept differences, distinguish subjects' reproductions of intervals presented first and second. For both the 1- and 6-sec ISIs, the approximated regression functions relating physical and reproduced time have greater acclivity for the more recently presented intervals. To test the reliability of this observation, subjects' regression slopes and intercepts for both presentation orders and both ISIs were submitted to an analysis of variance, and the results of this analysis supported the observation made above: The mean slopes for intervals presented first and second were significantly different for both the $1-\sec$ ISI [.499 vs. .626; $F(1,16)=9.31, p<.01]$ and the 6-sec ISI [.521 vs. $.635 ; F(1,16)=11.54, p<.01]$, and the intercept differences failed to reach conventional levels of significance $[F(1,16)<1.0$ for the $1-\sec$ ISI and $F(1,16)=3.59$ for the 6-sec ISI; $p>.05$ ]. Section 1 of Experiment 2 thus replicated the major finding of Experiment 1 in showing a negative TOE for both short and long intervals resulting from the greater sensitivity of the time-keeping mechanism to changes in time for the second interval.

The rationale for Section 2, as stated above, was to employ essentially the same experimental conditions used in Section 1 to investigate whether the results obtained in Section 1 had been unduly affected by considering only the first half of each subject's responses.

The data of 2 of the 18 subjects in Section 2 were excluded from analysis because they failed to follow instructions: the regression lines of these 2 subjects had negative slopes. These subjects, for example, reproduced, on average, a 13-sec interval as shorter than a 2-sec interval! We felt justified in excluding their data.

Table 3 and, respectively, Panels 3 and 4 of Figure 2 show the mean reproductions for both presentation orders for ISIs of 1 and $6 \mathrm{sec}$. Similar to the results of Section 1, Section 2 demonstrates a negative TOE: intervals presented second were reproduced longer than intervals presented first, and this presentation-order effect was again significant when collapsed over ISI length $[F(1,14)$ $=51.82, p<.001]$. Of the 16 subjects, 15 showed a negative TOE ( $p=.0002$ by a sign test). The least- 


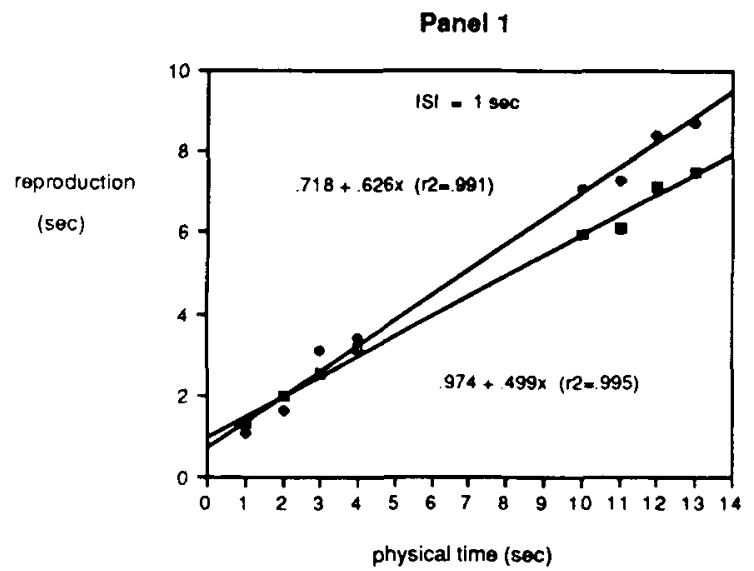

Panel 2
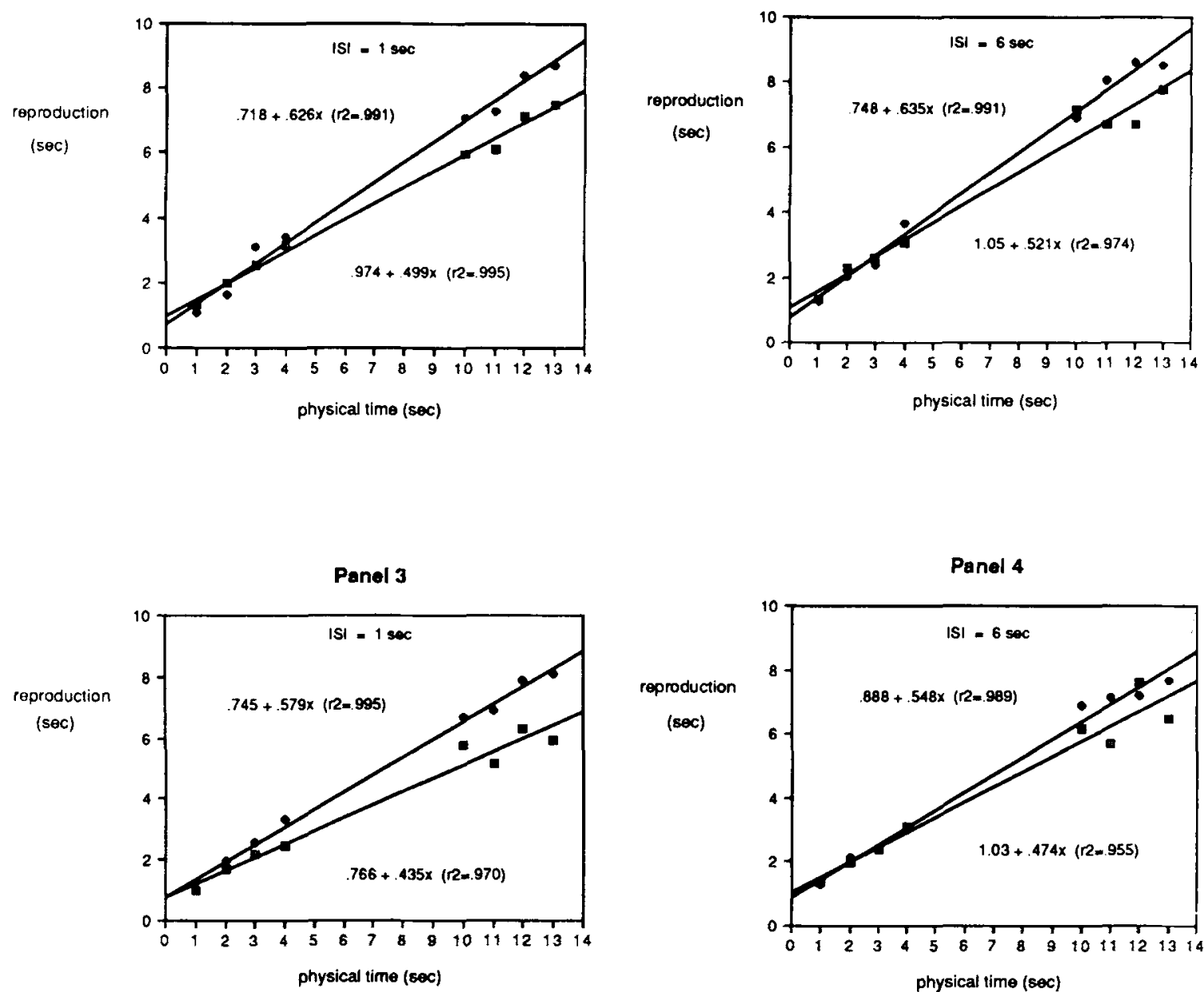

Panel 4

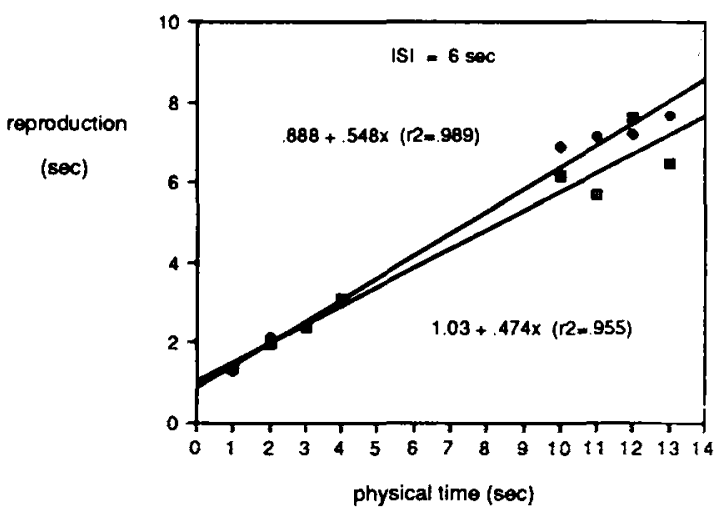

Panel 5

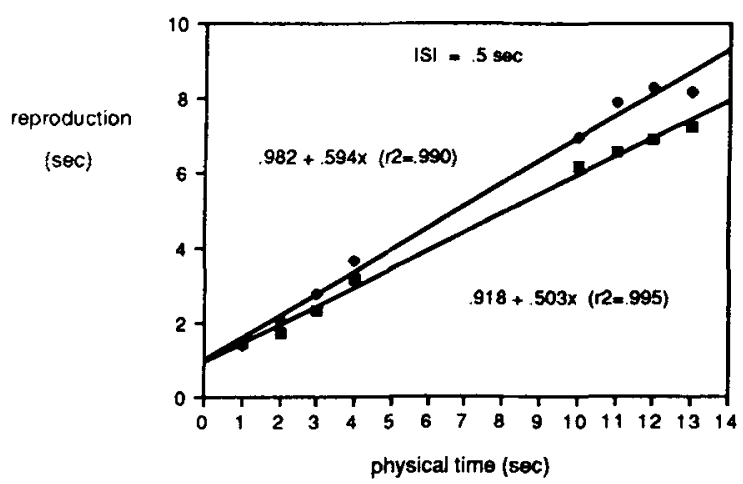

Panel 6

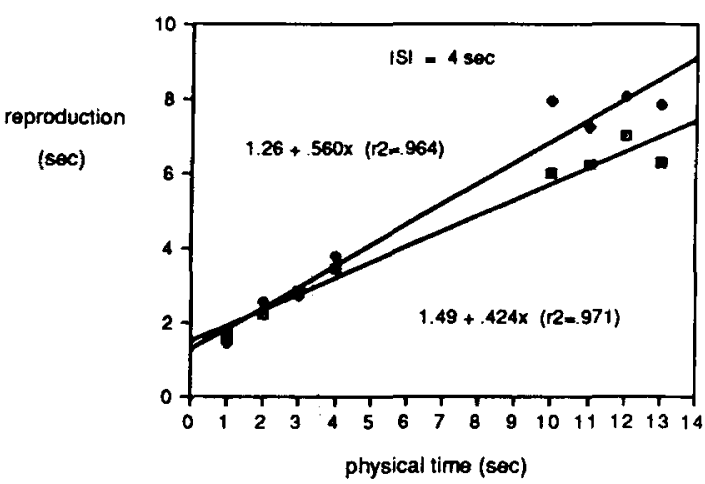

Figure 2. Mean reproductions for all eight stimulus intervals and both presentation positions in Experiment 2. Panels 1 and 2 represent the data of Section 1, Panels 3 and 4, the data of Section 2, and Panels 5 and 6, the data of Section 3. $\square=$ position $1 ; \bullet=$ position 2 . 
Table 3

Mean Interval Reproductions as a Function of Stimulus Interval (in Seconds) and Presentation Position for Experiment 2, Section 2 Stimulus Interval

\begin{tabular}{|c|c|c|c|c|c|c|c|c|c|}
\hline & \multicolumn{8}{|c|}{ Stimulus Interval } \\
\hline & & 1 & 2 & 3 & 4 & 10 & 11 & 12 & 13 \\
\hline \multicolumn{10}{|c|}{ ISI $=1 \mathrm{sec}$} \\
\hline Position 1 & $\begin{array}{l}M \\
S D\end{array}$ & $\begin{array}{l}.99 \\
.48\end{array}$ & $\begin{array}{r}1.66 \\
.75\end{array}$ & $\begin{array}{l}2.18 \\
1.50\end{array}$ & $\begin{array}{l}2.47 \\
1.31\end{array}$ & $\begin{array}{l}5.76 \\
3.64\end{array}$ & $\begin{array}{l}5.17 \\
3.40\end{array}$ & $\begin{array}{l}6.33 \\
3.87\end{array}$ & $\begin{array}{l}5.91 \\
3.95\end{array}$ \\
\hline Position 2 & $\begin{array}{l}M \\
S D\end{array}$ & $\begin{array}{r}1.01 \\
.42\end{array}$ & $\begin{array}{r}1.98 \\
.78\end{array}$ & $\begin{array}{r}2.53 \\
.81\end{array}$ & $\begin{array}{l}3.30 \\
1.31\end{array}$ & $\begin{array}{l}6.71 \\
3.32\end{array}$ & $\begin{array}{l}6.89 \\
3.69\end{array}$ & $\begin{array}{l}7.87 \\
3.65\end{array}$ & $\begin{array}{l}8.09 \\
3.72\end{array}$ \\
\hline \multicolumn{10}{|c|}{ ISI $=6 \mathrm{sec}$} \\
\hline Position 1 & $\begin{array}{l}M \\
S D\end{array}$ & $\begin{array}{r}1.33 \\
.71\end{array}$ & $\begin{array}{r}1.98 \\
.84\end{array}$ & $\begin{array}{l}2.37 \\
1.01\end{array}$ & $\begin{array}{l}3.13 \\
1.79\end{array}$ & $\begin{array}{l}6.18 \\
3.56\end{array}$ & $\begin{array}{l}5.70 \\
3.63\end{array}$ & $\begin{array}{l}7.61 \\
4.00\end{array}$ & $\begin{array}{l}6.49 \\
3.60\end{array}$ \\
\hline Position 2 & $\begin{array}{l}M \\
S D\end{array}$ & $\begin{array}{r}1.29 \\
.51\end{array}$ & $\begin{array}{r}2.14 \\
.57\end{array}$ & $\begin{array}{r}2.43 \\
.83\end{array}$ & $\begin{array}{r}3.00 \\
.96\end{array}$ & $\begin{array}{l}6.91 \\
2.34\end{array}$ & $\begin{array}{l}7.14 \\
2.84\end{array}$ & $\begin{array}{l}7.21 \\
3.92\end{array}$ & $\begin{array}{l}7.68 \\
2.96\end{array}$ \\
\hline
\end{tabular}

squares regression lines, moreover, indicated that slope differences, rather than intercept differences, characterize the negative TOE obtained in Section 2. An analysis of subjects' regression slopes and intercepts for both presentation positions demonstrated that the slopes for intervals presented as the second of the pair were steeper than the slopes for the intervals presented first. This difference is significant for both the 1-sec ISI [.579 vs. .435; $F(1,7)=38.16, p<.001]$ and the 6-sec ISI [.548 vs. $.474 ; F(1,7)=14.0, p<.01]$. None of the intercept differences between first and second presentation orders, however, was significant.

In summary, Section 2 essentially replicates the results of Section 1 and thereby allows us to rest assured that the exclusion of the second half of subjects' responses did not affect the results in any observable way. Section 2, however, also replicates Experiment 1 in showing a negative TOE for both short and relatively longer intervals and corroborates Experiment 1 in finding that slope differences, and not intercept differences, between the functions relating reproduced time to physical time for both presentation positions characterize the obtained TOE.

Section 3 repeated the experimental conditions of Section 2 with the following exception: ISIs of .5 and $4 \mathrm{sec}$ separated the two intervals of every trial. A preliminary examination of the basic statistics of Section 3 revealed the presence of numerous outliers. Therefore, prior to further statistical analysis, interval reproductions more than two standard deviations above or below the mean of that interval were excluded from analysis. By this procedure, 68 observations from a total of 1,152 were excluded from analysis and interpretation. A similar procedure was done on the data of Experiment 1 for comparison purposes, but, having no noticeable effect on that data, was abandoned in favor of the untrimmed data reported above.

The mean reproductions for this Section 3 are shown in Table 4 and are displayed in Panels 5 and 6 of Figure 2, respectively representing the data for ISIs of .5 and $4 \mathrm{sec}$. Both panels are plotted in the same way as the previous panels, and both also show the same pattern: a negative TOE at virtually all interval lengths. The overall presentation-position effect was again significant $[F(1,16)$ $=19.01, p<.001]$, and 17 subjects showed a negative TOE and only $l$ produced a positive one ( $p=.0001$ by a sign test). The analysis of the individual slopes and intercepts also confirmed the reliability of the visual impression of Panels 5 and 6 that the negative TOE was due to steeper slopes for intervals presented as the second of the pair at both the .5 -sec ISI $[F(1,8)=10.69, p<.05]$ and the 4-sec ISI $[F(1,8)=23.38, p<.01]$. Intercepts, however, were not significantly different between positions 1 and 2 ( $F<1.0$ for both ISIs). Section 3 thus confirmed the results of Experiment 1 and Sections 1 and 2 of Experiment 2, which indicated that when both short and long intervals are presented in the same experiment, the TOE tends to be universally negative. Moreover, both Experiments 1 and 2 support the interpretation that the TOE for interval reproduction is a function of the characteristics of the processing system rather than the result of acquired response or decision biases.

TOE and ISI. A total of five different ISI lengths were used in Experiments 1 and 2: .5, 1, 2, 4, and $6 \mathrm{sec}$. An initial analysis of variance performed on both slope and intercept differences between presentation positions 1 and 2 for all subjects of Experiments 1 and 2 showed no ISI effect $[F(4,83)<1.0]$. TOE neither increased nor decreased consistently with increases in ISI, and our experiments therefore do not support the claims of either early studies (e.g., Needham, 1935) that TOE size increases with ISI length or more recent studies (e.g., Jamieson \& Petrusic, 1975a) that TOE size decreases with ISI length.

A different analysis ${ }^{1}$ focused on the so-called indifference interval, the interval at which no TOE occurs. In the present context, this point represents the physical interval at which presentation order has no effect on interval reproduction; it can be found by calculating the point of intersection between the regression functions for both presentation positions. Figure 3 shows the mean physical interval at which TOE equals zero as a function of ISI. The data presented in Figure 3 were calculated from the equations depicted in Figures 1 and 2 and indicate that

Table 4

Mean Interval Reproductions as a Function of Stimulus Interval (in Seconds) and Presentation Position for Experiment 2, Section 3

\begin{tabular}{|c|c|c|c|c|c|c|c|c|}
\hline & \multicolumn{8}{|c|}{ Stimulus Interval } \\
\hline & 1 & 2 & 3 & 4 & 10 & 11 & 12 & 13 \\
\hline \multicolumn{9}{|c|}{$\mathrm{ISI}=.5 \mathrm{sec}$} \\
\hline $\begin{array}{rl}\text { Position } 1 & M \\
& S D\end{array}$ & $\begin{array}{r}1.47 \\
.59\end{array}$ & $\begin{array}{r}1.72 \\
.79\end{array}$ & $\begin{array}{l}2.33 \\
1.16\end{array}$ & $\begin{array}{l}3.14 \\
1.27\end{array}$ & $\begin{array}{l}6.15 \\
2.16\end{array}$ & $\begin{array}{l}6.57 \\
2.30\end{array}$ & $\begin{array}{l}6.90 \\
2.58\end{array}$ & $\begin{array}{l}7.24 \\
2.48\end{array}$ \\
\hline $\begin{array}{rl}\text { Position } 2 & M \\
& M D\end{array}$ & $\begin{array}{r}1.37 \\
.60\end{array}$ & $\begin{array}{r}2.04 \\
.65\end{array}$ & $\begin{array}{l}2.79 \\
1.22\end{array}$ & $\begin{array}{r}3.65 \\
.98\end{array}$ & $\begin{array}{l}6.94 \\
1.79\end{array}$ & $\begin{array}{l}7.88 \\
2.34\end{array}$ & $\begin{array}{l}8.28 \\
2.34\end{array}$ & $\begin{array}{l}8.15 \\
2.53\end{array}$ \\
\hline \multicolumn{9}{|c|}{ ISI $=4 \mathrm{sec}$} \\
\hline $\begin{array}{rl}\text { Position } 1 & M \\
& S D\end{array}$ & $\begin{array}{r}1.65 \\
.68\end{array}$ & $\begin{array}{l}2.21 \\
1.09\end{array}$ & $\begin{array}{l}2.86 \\
1.23\end{array}$ & $\begin{array}{l}3.42 \\
1.53\end{array}$ & $\begin{array}{l}5.99 \\
2.49\end{array}$ & $\begin{array}{l}6.22 \\
2.34\end{array}$ & $\begin{array}{l}7.01 \\
3.04\end{array}$ & $\begin{array}{l}6.29 \\
2.90\end{array}$ \\
\hline Position $2 \stackrel{M}{M}$ & $\begin{array}{r}1.43 \\
.66\end{array}$ & $\begin{array}{l}2.55 \\
1.16\end{array}$ & $\begin{array}{l}2.74 \\
1.06\end{array}$ & $\begin{array}{l}3.75 \\
1.30\end{array}$ & $\begin{array}{l}7.95 \\
2.36 \\
\end{array}$ & $\begin{array}{l}7.20 \\
1.90 \\
\end{array}$ & $\begin{array}{l}8.04 \\
3.00 \\
\end{array}$ & $\begin{array}{l}7.84 \\
2.66 \\
\end{array}$ \\
\hline
\end{tabular}


the interval at which no TOE occurs is an increasing function of ISI. A subsequent analysis of variance on the point of intersection between the regression lines for positions 1 and 2 for each subject and ISI confirmed the pattern of results shown in Figure $3[F(4,83)=3.05, p<.022]$. Thus, as ISI increases, the point at which TOE equals zero increases as well. This point, however, is also the point at which the sign of the TOE reverses, and, therefore, the range of intervals at which TOE is positive, rather than negative, increases as a function of the separation between stimulus intervals 1 and 2 . One possible, though speculative, interpretation of this effect is that as ISI increases, the shorter intervals presented in position 1 assimilate toward the ISI and are therefore judged as being longer than the same intervals presented second. However, any firm conclusions regarding this effect must await further and explicit study (e.g., manipulation of stimulus range).

Finally, as we suggested above, if the TOE is a manifestation of the recency effect in memory, then the primary effect of increasing ISI should be a decrease in accuracy of remembering the first interval of the pair. Moreover, this reduction in accuracy should be greatest for the long intervals, because a long first interval, in the present experiments, was always followed by a long second interval, thereby producing a considerable delay between the experience of the first interval and the cue to begin reproduction. In contrast, manipulating ISI length should have little effect on judgments of the second interval, since retention interval of the second interval is not affected by ISI.

Visual inspection of the data presented in Panels 1 through 6 of Figure 2 seems to indicate that the fit of the four mean reproductions for the long intervals presented in position 1 to their respective regression functions generally decreases as ISI increases, whereas no such pattern is observable for position 2 . This decrease is shown more directly in Figure 4, which presents the values of $r^{2}$ (as the measure of fit to regression functions) for the four long intervals presented in position 1 as a function of ISI. Figure 4 shows that $r^{2}$ is a monotonically decreasing func-

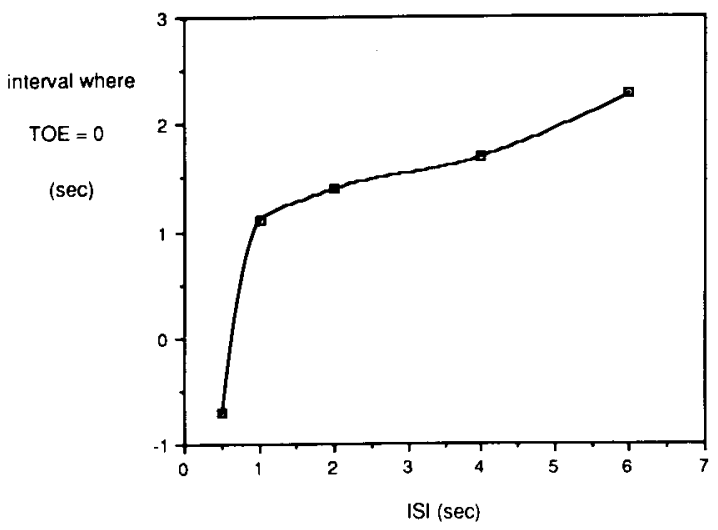

Figure 3. Physical intervals where TOE equals zero as a function of ISI.

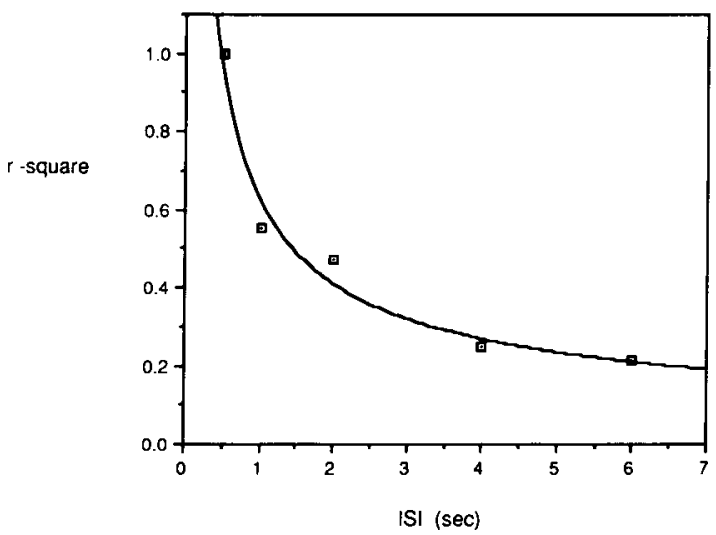

Figure 4. The $r^{2}$ values for the four long intervals presented in position 1 as a function of ISI.

tion of ISI. Thus, particularly for long intervals, as ISI increases, loss of information about the first interval becomes increasingly probable, and, consequently, subjects' reproductions of intervals presented as the first of the pair become less reliable. Accordingly, the role of the interstimulus interval is well described by the general empirical law of memory, that experiences that have occurred in the more distant past are subject to more forgetting than recent experiences-in other words, a recency interpretation.

The fading-trace theories of the TOE have suggested that the TOE increases with ISI due to the fading trace of the first interval. The data of the present experiments indicate, in contrast, that as the ISI increases, the probability of forgetting information concerning the first interval also increases, and that reproductions of the first interval will consequently become less and less accurate, that is, be an increasingly poor reflection of what the actual interval had been. Thus, according to our data, the main effect of ISI is not to reduce the remembered length of the more remote interval, thereby affecting the size of TOE, but to reduce the accuracy of remembering the first interval.

The present experiments provide no evidence for an effect of ISI on the size of TOE, and our data are thus in conflict with the claims reviewed above for a direct relationship between ISI and TOE magnitude. We are, of course, wiser than to suggest that two experiments can falsify an entire literature. However, we also note that the earlier results are collectively equivocal regarding the direction of the ISI-TOE relationship, and that the results of varying ISI reported here are consistent with a general memory principle, and so are not altogether negative. We suggest, in conclusion, that further investigation of the role of ISI on successive stimulus judgment will be productive only to the extent that it is guided by theory.

\section{GENERAL DISCUSSION}

The goal of the present experiments was to investigate the effects of presentation order on memory for temporal 
intervals. Of specific interest was (1) whether the TOE is the result of sensitivity or bias, (2) whether the direction of the TOE differs for short and long intervals, and (3) whether the length of the interstimulus interval affects the size of the TOE.

With regard to the source of the time-order error, our main result indicates that the TOE is due to the sensitivity of the processing system to the sequential presentation of time intervals, and not to a bias. By failing to plot the regression functions relating temporal judgment and physical time, and by relying on measures, such as proportion correct and degree of over- or underestimation, that inherently confound the sensitivity and bias dimensions of the phenomenon, previous investigations of presentationorder effects have been inadequate in their attempts to address the question concerning the cause of the TOE. For example, if subjects are more often correct when the second interval is longer than the first, are they correct because they are better able to process or remember longer intervals presented second, or because they have a tendency to judge intervals presented second as longer? A measure of proportion correct is unable to distinguish between these two possible sources of the TOE. In the present experiments, the analysis of the slopes and intercepts of the regression functions relating physical and reproduced time provided the means to separate sensitivity (slope) and bias (intercept) effects in the determination of the cause of the TOE. The results suggest that for the sequential presentation of temporal intervals in specific, and perhaps for the sequential presentation of stimuli in general, the existence of presentation-order errors is due to the sensitivity of the processing mechanism to different serial positions of sequential stimuli. We have discussed this sensitivity difference in terms of the recency effect in memory: Whatever information is used to remember accurately time intervals from the past is more accessible for the more recent of two intervals than for the more distant. However, before any more complete explanation of the "sensitivity-character" of the TOE is articulated, the precise conditions under which positive, rather than negative, TOEs occur must be understood.

In the experiments described here, negative TOEs were obtained for both relatively short and relatively long intervals: Intervals were consistently reproduced longer when they had been presented as the second of the pair. However, our experiments differ in two crucial aspects from studies that have found positive TOEs for short intervals. First, while the shortest interval in our experiments was $1 \mathrm{sec}$, many of the studies that found positive TOEs used intervals shorter than $1 \mathrm{sec}$. Second, the studies that have obtained positive TOEs have generally employed a relatively restricted range of intervals, whereas in the present experiments a fairly wide range of intervals was used. Whether one or both of these factors are necessary for the occurrence of a positive TOE was not addressed in the present experiments, but may be answered easily with more experimentation. It is worth noting, however, that in some of our own experiments, described elsewhere (e.g.,
Crowder \& Greene, 1987, Experiments 1 and 3; Schab \& Crowder, 1987, Experiment 1), in which the stimulus range was quite restricted (i.e., .5 to $3 \mathrm{sec}$ ), positive, rather than negative, TOEs were obtained.

Finally, the failure to obtain a reliable relationship in the present study between the magnitude of the TOE and the length of the ISI, although in conflict with the literature, was congruent with the recency interpretation of sequential stimulus presentation discussed in the present paper. Rather than an increase or decrease in mean reproduction of intervals presented first as opposed to second, the recency interpretation predicts that reproduction of the first interval will become less accurate as the ISI increases because memory for the first interval is increasingly subject to forgetting. This pattern of results was, subsequently, borne out.

In conclusion, the role of succession in judging stimuli, due to its omnipresence, is essential to a general theory of how humans process information, and continued research on successive stimulus presentation and its effects on comparisons, judgments, and decisions represents a significant contribution to this end.

\section{REFERENCES}

ALLAN, L. G. (1977). The time-order error in judgments of duration. Canadian Joumal of Psychology, 31, 24-31.

AllaN, L. G. (1978). Comments on current ratio-setting models for time perception. Perception \& Psychophysics, 24, 444-450.

BADdeley, A. D., HrTCh, G. J. (1977). Recency reexamined. In S. Dornic (Ed.), Attention and performance $V I$ (pp. 647-667). Hillsdale, NJ: Erlbaum.

BJoRk, R. A., \& Witten, W. B. (1974). Recency-sensitive retrieval processes in long-term free recall. Cognitive Psychology, 6, 173-189.

BoAs, F. (1882). Über die verschiedenen Formen des Unterschiedsschwellenwertes. Pfager's Archiv für Physiologie, 27, 214-222.

Crowder, R. G. (1976), Principles of learning and memory. Hillsdale, NJ: Erlbaum.

Crowder, R. G., Greene, R. L. (1987). On the remembrance of times past: The irregular list technique. Joumal of Experimental Psychology: General, 116, 265-278.

EISLER, H. (1975). Subjective duration and psychophysics. Psychological Review, 22, 429-450.

Engen, T. (1971). Psychophysics: 1. Discrimination and detection. In L. A. Kling \& J. W. Riggs (Eds.), Woodworth and Schlosberg's experimental psychology (pp. 11-46). New York: Holt, Rinehart, \& Winston.

FrChner, G. T. (1860). Elemente der Psychophysik. Leipzig: Breitkopf \& Haertel.

FetTerman, J. G., \& Dreyfus, L. R. (1987). Duration comparisons and the perception of time. In M. L. Commons, J. E. Mazur, J. A. Nevin, \& H. Rachlin (Eds.), Quantitative analyses of behavior: Vol. 5. The effects of delay and intervening events on reinforcement value. Hillsdale, NJ: Erlbaum.

Fraisse, P. (1948). Les erreurs constantes dans la reproduction de courts intervalles temporels. Archives de Psychologie, 32, 161-176.

GeERTSMA, R. H. (1958). Time-order errors in comparative judgments of hurtfulness. Journal of Experimental Psychology, 55, 284-288.

Glanzer, M., Cunitz, A. R. (1966). Two storage mechanisms in free recall. Jownal of Verbal Learning \& Verbal Behavior, 5, 351-360.

Greene, R. L. (1986). Sources of recency effects in free recall. Psychological Bulletin, 99, 221-228.

Guilford, J. P. (1954). Psychometric methods (2nd ad.). New York: McGraw-Hill.

Hellström, A. (1977). Time errors are perceptual. An experimental 
investigation of duration and a quantitative successive-comparison model. Psychological Research, 39, 345-388.

Hellström, A. (1985). The time-order error and its relatives: Mirrors of cognitive processes in comparing. Psychological Bulletin, 97, 35-61.

HELSON, H. (1964). Adaptation-level theory. New York: Harper \& Row.

Jamieson, D. G., \& Petrusic, W. M. (1975a). The dependence of timeorder error direction on stimulus range. Canadian Journal of Psychology, 29, 175-182.

Jamieson, D. G., \& Petrusic, W. M. (1975b). Presentation order effects in duration discrimination. Perception \& Psychophysics, 17, 197-202.

KöHLER, W. (1923). Zur Analyse des Sukzessivvergleichs und der Zeitfehler. Psychologische Forschung, 4, 115-175.

Lauenstein, O. (1933). Sukzessivvergleich von gebogenen Linien. Psychologische Forschung, 22, 343-371.

LUCE, R. D. (1959). Individual choice behavior. New York: Wiley.

Luce, R. D., Galanter, E. (1963). Discrimination. In R. D. Luce, R. R. Bush, \& E. Galanter (Eds.), Handbook of mathematical psychology (Vol. 1, pp. 191-243). New York: Wiley.

NAveh-Benjamin, M., Jonides, J. (1986). On the automaticity of frequency coding: Effects of competing task load, encoding strategy, and intention. Joumal of Experimental Psychology: Leaming, Memory, \& Cognition, 12, 378-386.

Needham, J. G. (1934). The time-error in comparison judgments. Psychological Bulletin, 31, 229-243.

Needham, J. G. (1935). The effect of the time interval upon the timeerror at different intensive levels. Journal of Experimental Psychology, 18, 530-534.

OrnsteIn, R. E. (1969). On the experience of time. New York: Penguin.

Postman, L. (1947). Time-errors as a function of the method of experimentation. American Journal of Psychology, 60, 101-108.

SCHAB, F. R., CRowder, R. G. (1987). Accuracy of temporal coding: Auditory-visual comparisons. Unpublished manuscript.
StÄrke, P. (1886). Die Messung von Schallstaerken. Philosophische Studien, 3, 268.

Stotr, L. H. (1935). Time-order errors in the discrimination of short tonal durations. Journal of Experimental Psychology, 18, 741-766.

StubBs, D. A. (1976). Response bias and the discrimination of stimulus duration. Journal of the Experimental Analysis of Behavior, 25, 243-250.

Tresselt, M. E. (1948). Time-errors in successive comparison of tonal pitch. American Journal of Psychology, 61, 335-342.

VIERORDT, K. (1868). Der Zeitsinn nach Versuchen. Tübingen, Germany: Laupp.

Watkins, M. J., Peynircioglu, Z. F. (1983). Three recency effects at the same time. Joumal of Verbal Leaming \& Verbal Behavior, 22, 375-384.

Wolfe, H. K. (1898). The size of familiar objects. American Journal of Psychology, 9, 137.

WoODRow, H. (1933). Weight discrimination with a varying standard. American Journal of Psychology, 45, 391-416.

Woodrow, H. (1935). The effect of practice on time-order errors in the comparison of temporal intervals. Psychological Review, 42, 127-152.

WoODWORTH, R. S. (1938), Experimental psychology. New York: Holt, Rinehart, \& Winston.

\section{NOTE}

1. We would like to thank Alfred B. Kristofferson for suggesting this analysis.

(Manuscript received September 28, 1987; revision accepted for publication March 3, 1988.) 